\title{
Entender a educação como um acto de cultura: estratégias de formação artística $^{1}$
}

Anabela Moura²

\begin{abstract}
Resumo
É confiada ao sistema escolar Português a função primordial de contribuir para a compreensão e preservação do património, sendo que a educação patrimonial é uma componente importante da Educação Artística em Portugal. Um problema central no seu estudo é a falha do sistema escolar na consecução das finalidades atrás descritas, porque o seu ensino é feito de uma forma muito etnocêntrica*, ignorando as culturas minoritárias e as culturas não Europeias. Este artigo explora diversas abordagens educativas e apresenta estratégias utilizadas por professores de Cursos de Arte da Formação Inicial e Mestrado, que têm trabalhado com o Departamento de Educação Artística da Escola Superior de Educação, do Instituto Politécnico de Viana do Castelo (ESEVC), Portugal. Os presentes Projectos tiveram as seguintes finalidades: (1) reflectir sobre educação artística usando literatura predominantemente Anglo-Saxónica; (2) desenvolver uma prática reflexiva; e (3) utilizar os princípios fundamentais da investigação educativa. No final apresentam-se algumas conclusões e implicações para o contexto da educação em geral e especificamente para o Projecto Internacional em curso entre a ESEVC e Universidades de Ensino Superior do Brasil (e.g. Belo Horizonte, Uberaba \& Campinas), intitulado Experiências D'Além Mar: Estudos Luso-Brasileiros sobre Cultura, Educação e Educação em Arte.
\end{abstract}

Palavras Chave: Educação Artística; Educação Patrimonial;

\begin{abstract}
In Portugal, the school system is charged with an essential function in relation to the understanding and preservation of patrimony, and patrimony education is an important element of art education. A core problem in its study is the failure of the school system to fulfill such aims because the teaching of this concept is done in an ethnocentric way and ignores minority and non-European cultures. This article explores different educational approaches and presents strategies used by undergraduate and postgraduate teachers who have been working on Art Degree Courses in the Art Education Department, at the Teacher Training College of Viana do Castelo Polytechnic (ESEVC), Portugal. The present Projects had the following aims: (i) to reflect on artistic education through a review of literature especially Anglo-Saxon; (ii) to develop reflective practice; and (iii) to use the fundamental principles of educational research. Finally, some findings, conclusions and implications for educational contexts in general are presented specifically for the present international Project of scientific cooperation between ESEVC and Brazilian Universities (eg. Belo Horizonte, Uberaba \& Campinas), entitled Experiences of Overseas Luso-Brazilian Studies of Culture, Education and Art Education.
\end{abstract}

Key words: Art Education; Heritage Education;

\footnotetext{
${ }^{1}$ Para publicação foi mantido o formato da escrita em português de Portugal. (Nota da Editora).

2 PhD, Surrey Roehampton University, Londres, MA De Montfort University Leicester, Licenciada FBAUP, Coordenadora do Departamento de Artes, da Escola Superior de Educação. Directora dos Cursos de $1^{\circ}$ e $2^{\circ}$ Ciclos de Estudos de Gestão Artística e Cultural. Professora Adjunta no Instituto Politécnico de Viana do Castelo. amoura@ese.ipvc.pt
} 


\section{Introdução}

Para uma maior compreensão da investigação que tenho orientado na área da educação artística e patrimonial, começarei por descrever, de forma sintética, o que se passou ao longo de cinco anos, entre 2000 e 2005 (após a conclusão do meu Doutoramento), em termos de pesquisa de teorias e práticas de educação artística e como as mesmas têm sido adaptadas e testadas no nosso contexto, através de métodos qualitativos, essencialmente. Começo pela teoria e análise dos conceitos de arte e a forma como eles têm sido interpretados, segundo o que me tem sido dado a observar, ao longo de trinta e seis anos de experiência lectiva, em escolas de diversos graus de ensino.

No mundo ocidental e Portugal não é excepção, a arte é bastante diferente da do resto do mundo, em muitos aspectos. Allison (1992), investigador inglês, refere que a arte ocidental, que é basicamente europeia, se desenvolveu segundo um modelo histórico muito forte e linear, com normas, formas e materiais próprios, determinando a sua própria função na sociedade, inventando ou criando os seus próprios significados e incorporando-os em trabalhos de arte.

Segundo Allison, os papéis desempenhados pelos artista, crítico, coleccionador, especialista e galerista, estão claramente definidos na cultura ocidental, formatando um conceito específico de arte ligado a diversos aspectos tais como: para que serve; a quem se dirige; a série de ideias e sentimentos que incorpora e comunica, as formas que assume, os locais onde pode ser encontrada e, acima de tudo, a relação que estabelece com as pessoas. Todavia, a arte do mundo ocidental é só um tipo de arte e as suas características e natureza específica (como produto de culturas particulares) só podem ser totalmente compreendidas através de uma comparação entre ela e a arte das outras culturas. McFee \& Degge (1977, p.276), afirmam que os multiculturalistas acreditam que o termo arte envolve "todas as coisas feitas pelos seres humanos, motivados pela tentativa de enriquecer a mensagem, melhorar a forma ou estrutura de um objecto e desenvolver no observador uma consciência qualitativa relativamente ao conteúdo", entendendo ainda que há tantos tipos de arte como culturas e subculturas.

Allison (1992) afirma que a arte e o ensino da arte são dois aspectos da cultura, considerada esta como todos os aspectos do empreendimento humano, que caracterizam o património de qualquer sociedade em particular e que inclui a língua, formas diversas de conhecimento, imagens, música, religião, economia, política e tantos outros aspectos que são a base do desenvolvimento das atitudes, dos valores e das crenças. Para além da cultura ser essencial na vida de cada indivíduo e de cada sociedade, é também um elemento fundamental de comunicação entre as pessoas e pode contribuir para fortalecer 
a compreensão ao nível nacional e internacional, através do reconhecimento de diferentes formas de expressão e de diferentes valores culturais das sociedades.

A análise dos currículos do $1^{\circ}$ e $2^{\circ}$ ciclos em Portugal permitiu identificar influências transculturais na história colonial portuguesa, que têm sido negligenciadas por grande parte de professores/as de todos os níveis de ensino e áreas disciplinares. Essa análise permitiu a constatação de grande número de preconceitos e estereótipos nas abordagens feitas por professores desse nível de ensino, em termos de educação patrimonial, resultado do etnocentrismo dos currículos de educação artística. A forma como é explorado nas escolas não reflecte a natureza multicultural da sociedade à qual professores e alunos pertencem. Pela forma como é abordado o conceito de património, constatou-se que, nos currículos de artes do $1^{\circ}$ e $2^{\circ}$ ciclos, este era mais monocultural do que culturalmente diverso, pois não inclui as artes dos chamados países em desenvolvimento e ignora que o nosso país é multicultural e multiracial.

Não foi simples definir o termo património pois, apesar deste estar sempre enfatizado fortemente no ensino obrigatório, a sua definição, dada por educadores, políticos, arqueólogos, antropólogos, sociólogos, historiadores, arquitectos e etnólogos e outros, difere enormemente. A definição usada nestas investigações foi a seguinte: Património é - meio cultural e ambiental existente, que inclui tudo que seja de natureza arquitectónica, arqueológica, histórica, religiosa, natural, etnológica e literária. Por outras palavras, é tudo o que os nossos antepassados e contemporâneos nos deixaram, o que significa todos os vestígios de intervenção humana que caracterizaram as sociedade do passado e continuam a caracterizar no presente e que consideramos que devem ser necessariamente preservados para as gerações futuras, porque representam a nossa cultura (MOURA, 2002).

Todos fazemos parte de uma cultura e esta molda a nossa visão sobre nós e sobre o mundo. As culturas diferem de muitas formas e é um facto que só podemos ter consciência da nossa cultura, se tivermos consciência das outras. A arte é um fenómeno da cultura e aceita-se, cada vez mais, que ela não é universal, no sentido de haver uma linguagem comum da arte. Tal como acontece com a linguagem verbal, a arte em culturas diferentes tem formas e sentidos diferentes, incorpora ideias, valores, atitudes e crenças diferentes e significa coisas diferentes na vida das pessoas.

No campo da educação artística continua a enfatizar-se quase exclusivamente o domínio da produção artística dos alunos e as actividades que abordam os conceitos de cultura e património limitam-se vulgarmente ao desenho de observação, à representação gráfica 
de artefactos históricos e à recolha de factos históricos isolados dos seus contextos sociais e culturais, tendendo-se a perpetuar a desigualdade e não dando a possibilidade aos estudantes de entenderem o conceito de cultura como um corpo de tradições, conhecimentos, costumes, práticas de pessoas em particular, cultura essa que é influenciada pelo passado, mas está continuamente a ser recriada como reacção à interacção e troca intercultural.

Por um lado a análise dos currículos, dos manuais escolares, de outras fontes que contribuem para a preparação prévia dos professores, das orientações que têm sido dadas à educação em geral e, por outro lado, a quantidade de problemas de aprendizagem que filhos de emigrantes e outras crianças de diversos sub - grupos e/ou grupos étnico minoritários têm demonstrado, são a evidência que os actuais currículos são inadequados à actual população multicultural. As relações entre culturas tem vindo a tornar-se uma questão muito significativa e, embora esta situação tenha acarretado um desenvolvimento enorme ao nível da investigação educacional, muita dessa literatura não tem sido traduzida para Português o que tem tornado a análise destas questões mais lenta e difícil. A abertura das fronteiras nacionais e culturais forçou muitos educadores ao nível mundial a repensar e reavaliar teorias e práticas, currículos, a reconhecer a existência de outras concepções de Património e a repensar o seu contributo na promoção da identidade e auto-estima de cada ser humano.

Neste contexto, a minha preocupação, em termos de formação de professores e de gestores das artes e da cultura, tem-se relacionado com a análise de fenómenos culturais e o envolvimento dos estudantes no exame de modelos internacionais multiculturais que desafiem e denunciem práticas correntes, testem e avaliem estratégias curriculares no contexto de sala de aula e utilizem materiais educativos que não contenham estereótipos, omissões e distorções. Várias questões são levantadas ao longo das intervenções curriculares, no sentido de se encetar uma mudança ao nível do currículo de Educação Artística nos diversos níveis de ensino e visando a promoção de uma política coerente de reforma educativa na sociedade Portuguesa.

\section{Projectos de Investigação sobre educação patrimonial}

Diversos projectos artísticos da Formação Inicial e investigações do Curso de Mestrado têm sido realizados utilizando essencialmente métodos qualitativos que reflectem formas diversas de promoção de valores, através da abordagem de temáticas diversificadas. Estratégias de crítica de arte foram usadas pelos professores estagiários como principal 
ferramenta de reforma multicultural e patrimonial e isso envolveu a familiarização com um número de estratégias críticas anglo-saxónicas (FELDMAN, 1982; TAYLOR, 1986).

Estas estratégias têm ajudado as crianças envolvidas a analisar imagens de forma estruturada. Em termos práticos, a análise de imagens e os métodos semióticos de crítica de arte desenvolveram-se a partir da preparação de materiais visuais que incluem imagens de revistas e jornais, diapositivos e acetatos de pinturas históricas de mestres famosos, de obras de arte contemporânea e o uso de publicidade da TV e de outros meios de comunicação. As imagens foram escolhidas de forma a estimular muita discussão e polémica e serviram de pretexto para explorar conceitos multiculturais tais como cultura, património, discriminação, preconceito, diversidade cultural, racismo e muitos outros. Elas permitem experiências significativas com as diversas artes e saberes disciplinares, com o uso de metáforas e com a interpretação simbólica do mundo, tendo como finalidade o desenvolvimento de competências gerais e transversais que permitam a formação de espectadores críticos e participativos.

Diversos são os investigadores que têm vindo a defender a inclusão dos meios de comunicação social na escola como um estímulo à auto expressão dos jovens pois a utilização das novas linguagens significa para os jovens a ruptura com velhos estereótipos. Conscientes do papel da música, do cinema, da BD, dos videoclips e da publicidade no quotidiano dos nossos jovens, têm-se programado intervenções curriculares relacionadas com problemáticas diversas. É o caso dos projectos acima mencionados, onde reflexões, ideias e conceitos foram desenvolvidos e serviram de base para uma leitura mais crítica e fundamentada da arte canonizada e das produções culturais de massa, obrigando os intervenientes a ver o mundo com um olhar mais cuidadoso e preparado para interpretar o quotidiano.

Como estratégia de investigação os professores ou futuros gestores pesquisam anúncios de jornais e revistas, artesanato, artefactos de culturas diversas, festas populares e situações em que as imagens, os sons e as letras, de diferentes origens culturais e locais se influenciam mutuamente, diluindo fronteiras que separam as manifestações do quotidiano das manifestações artísticas consagradas pela história oficial da arte. Junto com as crianças exploram-se temas de conscientização ecológica, estabelecem-se debates sobre o graffiti como forma de intervenção artística, sobre a cultura de rua e a forma como questões como a miséria e a guerra têm afligido e influenciado artistas ao longo de séculos. 
Em "Provérbios Populares", Barreto, professora estagiária do Curso de Educação Visual e Tecnológica (EVT) da Formação Inicial, alertou as crianças com idades compreendidas entre os dez e os doze anos, para a necessidade de conhecer e divulgar o património oral e o património dos valores sociais e culturais, através de actividades artísticas.

embora não seja viável o ensino directo de valores, a escola pode estimular o raciocínio moral, recorrendo à discussão de dilemas e à participação na tomada de decisões (In PATRÍCIO, 1997, p. 413).

Segundo esta professora estagiária, é preciso que as crianças participem num processo educativo que seja capaz de solidificar valores fazendo, segundo Patrício (1997, p.413), com que a criança se habitue a aceitar o outro tal como ele é, enquanto se forma a si próprio, de forma a que não escolham determinados valores em prejuízo de outros mas se habituem a reflectir sobre questões éticas, familiarizando-se com o processo de aquisição desses valores. As actividades desenvolvidas com preocupações interdisciplinares demonstraram às crianças o valor histórico e estético das tradições e também o seu valor educativo.

Os provérbios são frases sentenciosas de fins didácticos ou morais que abrangem todo o universo da vida do povo. (PERAFITA, 1999, p. 82)

Santos (1999, p.7) reforça esta ideia afirmando que os provérbios nos dão indicações para a vida, nos interrogam, enriquecem as nossas conversas e traduzem a nossa maneira de pensar. Assim, as actividades desenvolvidas ao longo de dezasseis aulas promoveram o acesso e a compreensão de diversas linguagens e alertaram para o desaparecimento gradual e irreversível dos ambientes naturais que viabilizam a literatura popular de tradição oral e de uma boa parte de uma sabedoria cujo uso apenas tem sentido na oralidade. Com a ajuda de imagens diversas, foi possível às crianças tomarem contacto com problemas sociais do passado e do seu quotidiano presente, o que thes permitiu desenvolver uma análise crítica, tal como está preconizado nas Competências Específicas do Programa Nacional (2001) 


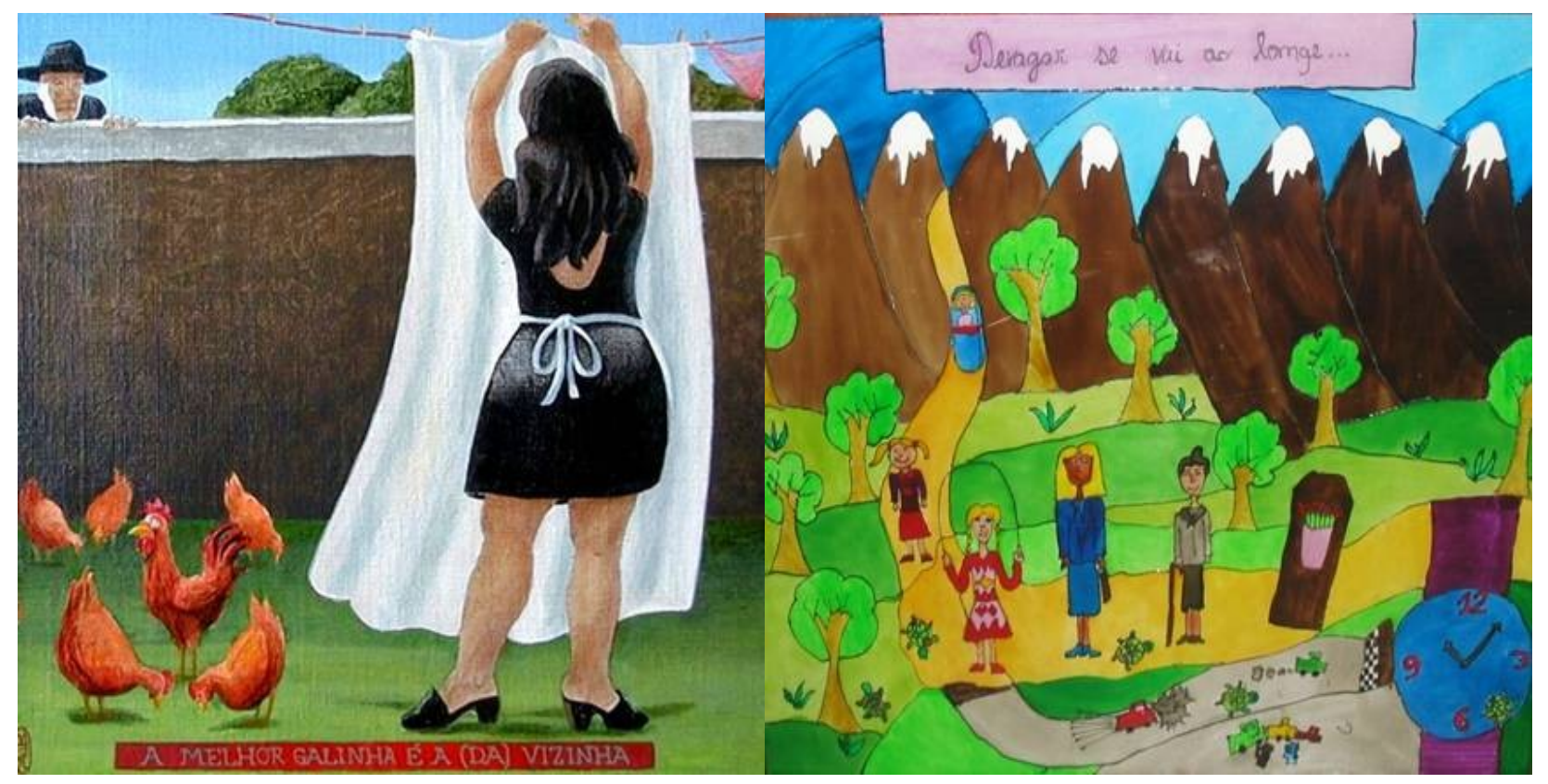

Fig.1: A melhor galinha é a da minha vizinha,

Fig. 2: Devagar se vai ao longe- Md, 10 anos Nuno Barreto

Máscaras dos Índios de Jurupixuna, Brasil, de Braga, (2003) alertou outras crianças, do mesmo nível etário para o processo de destruição que a floresta amazónica está a sofrer, quer a nível ambiental, quer a nível humano (e.g. Índios Jurupixuna). Com marcas expressivas das dos Índios Jurupixuna, a construção de máscaras surgiu como resultado de uma conscientização para os problemas decorrentes da desflorestação da floresta da Amazónia e para o reconhecimento da existência e valorização de outras culturas.

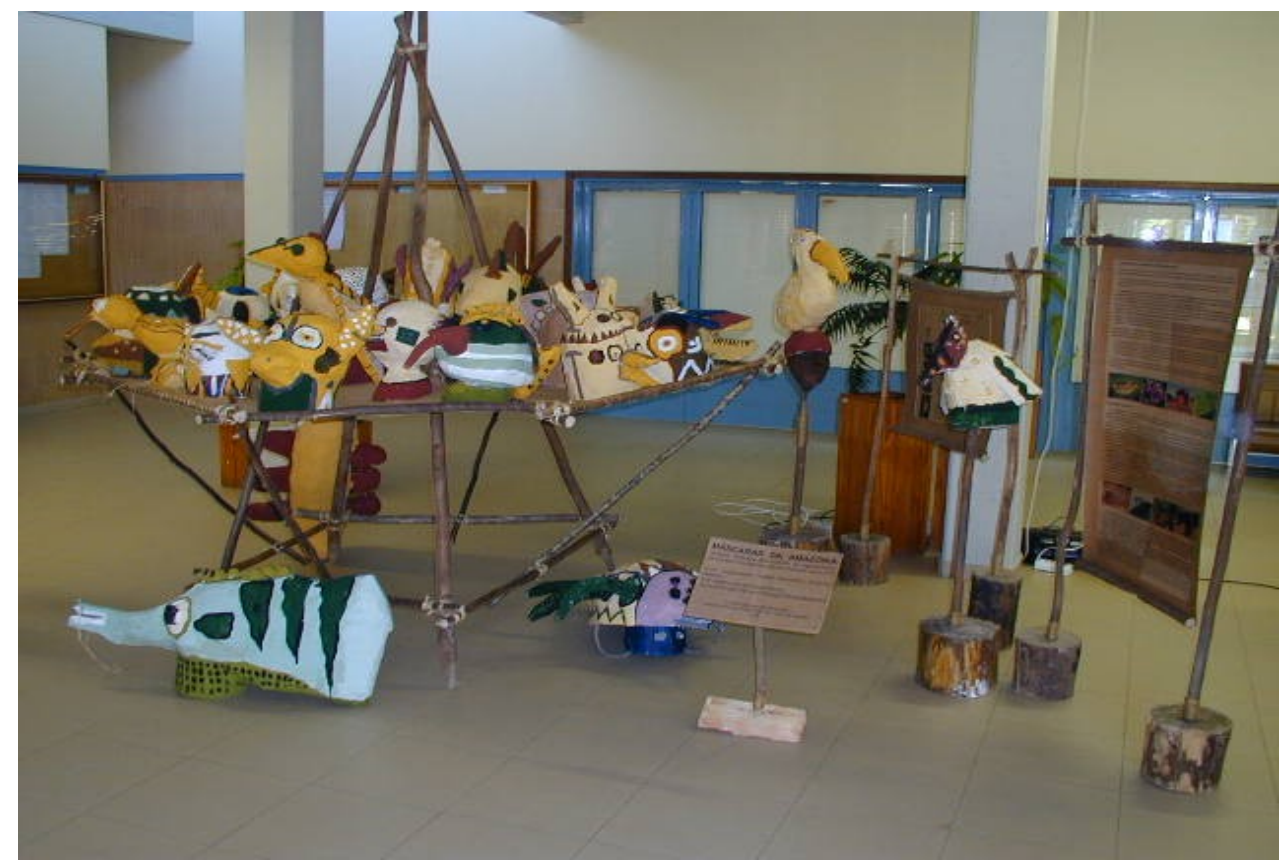

Fig. 3: Exposição Final das Máscaras 
O facto de se usarem materiais reciclados para construir as máscaras, permitiu aos alunos compreender que podem reutilizar objectos do quotidiano que, normalmente, não valorizam e deitam ao lixo. As crianças confrontaram-se com formas de arte de outros continentes, com características estéticas e tecnológicas diferentes das da arte ocidental e reflectiram sobre o simbolismo de artefactos e as relações ao nível do design e respectiva função. Ao convidar os seus alunos a olhar objectos da cultura material, o professor estabeleceu relações entre a arte e a antropologia e reflectiu sobre estereótipos culturais relacionados com grupos étnico - minoritários e a utilização indevida do conceito de ' primitivo'. As actividades relacionadas com crítica de arte e ensino interdisciplinar foram consideradas 'uma via natural' para ajudar os estudantes a encontrarem o 'outro' e a viverem caminhos culturalmente diferentes de estarem no mundo.

Ambas as intervenções curriculares utilizaram o método de investigação - acção por se considerar um meio eficaz para desenvolver uma reforma curricular multicultural, pois foram implementadas no contexto escolar, envolveram a colaboração de outros professores e permitiram a partilha de ideias, a reflexão e a avaliação sistemática de práticas. A observação foi considerada um instrumento importante de recolha de dados, uma vez que permitiu diagnosticar as necessidades e respostas dos intervenientes, em primeira mão e levou-os a tornarem-se mais flexíveis e críticos do seu ensino e a responderem mais às necessidades individuais das crianças. Outro factor positivo, que afectou o entendimento dos professores sobre os modelos de desenvolvimento curricular que estavam a testar, foi o feedback (verbal e visual) dado pelas crianças. A reflexão e avaliação sistemáticas contribuíram para o desenvolvimento da aprendizagem e o aperfeiçoamento de actividades e estratégias de ensino adaptadas às várias necessidades das turmas e de cada aluno.

Viana do Castelo é uma zona predominantemente monocultural, onde os contactos com realidades, crenças e formas de vida alternativas nos chegam essencialmente através dos meios de comunicação. Não podemos esquecer a força que a imagem e o som sempre tiveram e continuam a ter, não apenas no âmbito do ensino artístico como em muitas outras disciplinas, aparecendo em manuais, enciclopédias e outras fontes audiovisuais e que, juntamente com os métodos curriculares, constituem importantes veículos de informação. No entanto aparecem-nos, em muitos recursos educativos, imbuídas de estereótipos de género, raciais e de classe, reflectindo valores culturais da maioria dominante e de desigualdade social, reforçando e refinando uma redutora e deseducativa concepção do mundo. 
Estávamos conscientes disso, tendo sido, por isso, muito criteriosos na selecção de materiais. Os meios de comunicação tornaram-se um importante recurso de ensino/aprendizagem e as gravações em vídeo de programas, via TV, por cabo ou satélites, contribuíram significativamente para alargar as perspectivas dos estudantes sobre outras culturas. Como regra de ouro, os recursos desenvolvidos e usados nas intervenções foram desenhados para desenvolver competências perceptuais, históricas e críticas, necessárias ao entendimento e apreciação da arte e, ao mesmo tempo, aumentar a sua consciência para questões sociais e culturais. Estas intervenções curriculares não lidaram com números significativos de alunos de grupos étnico minoritários, mas focaram essencialmente os do grupo social maioritário, culturalmente tendencioso e na linha da ideologia dominante da escolaridade Portuguesa. A prioridade foi a de chamar a atenção de todos para os conflitos étnicos na sociedade Portuguesa e para as suas causas.

Ao nível da formação profissional, verificaram-se algumas mudanças do estilo de gestão de aula destes professores estagiários, reflectindo uma maior flexibilidade, contribuindo para um ambiente de aprendizagem mais vivo e dinâmico, reforçado por outras estratégias de ensino/aprendizagem tais como o jogo e a interacção com convidados. Embora não haja muita tradição nas escolas de ouvir os alunos, essa prática tornou-se uma parte essencial destas investigações-acção pois, tal como Kendall (1996, p.137) sugere "As mentes e os corações que se abrem às outras culturas e questionam estereótipos, respostas individuais, culturais e artísticas devem necessariamente estar envolvidos em diálogos permanentes".

A força do ensino/aprendizagem colaborativo destas investigações residiu no desafiar a situação tradicional em algumas salas de aula do Norte de Portugal, onde habitualmente todo o poder costuma estar nas mãos do professor. Os professores participantes (estagiários, cooperantes e supervisora pedagógica), deliberadamente, investiram num tipo de discussão e diálogo que encorajou todos a expressarem os seus sentimentos à medida que os projectos se desenvolviam. Este tipo de diálogo foi necessário para o desenvolvimento de competências gerais, transversais, interculturais, que permitiram, a todos os alunos, oportunidades de igualdade ao nível educativo.

A noção de cultura de sucesso deu lugar à noção de cultura de solidariedade e ao desenvolvimento de valores personalistas, não tradicionalistas ou utilitários. 0 desenvolvimento desses valores personalizados só foi possível graças à criação de um espaço de relação interpessoal de que fala Vieira (1993) e que ajudou a responsabilizar e a comprometer sistematicamente. As estratégias colaborativas de ensino/aprendizagem 
promoveram a partilha de crenças e valores culturais e de preocupações universais e o intercâmbio de experiências de adultos com crianças foi considerado muito enriquecedor. Esse diálogo gerado entre alunos e professores, através da discussão de conceitos e experiências, encorajou e fortaleceu a interacção social. Com isso, os professores acreditaram e esperaram que os seus alunos pudessem melhorar o seu autoconhecimento e compreensão, tanto da sua herança cultural como da dos outros.

A conclusão mais importante destas intervenções curriculares, desenvolvidas no âmbito da disciplina de Prática Pedagógica que oriento, é que a mudança na educação patrimonial necessita de muito questionamento, de trazer à luz valores e crenças culturais inconscientes expressas através de estereótipos. O que motivou estes professores estagiários não foi o ideal assimilacionista de integrar as crianças das minorias étnicas na sociedade das maiorias, transformando sistematicamente a diferença em desigualdade, mas o ideal construtivista de despertar as consciências de todos os participantes (alunos e professores) para os preconceitos e estereótipos existentes e preparar os estudantes estagiários, futuros professores de arte, para um papel interventivo (MOURA, 2010).

As investigações destes e de muitos outros desafiaram-nos a desenvolver uma abordagem pluralista em termos de ensino da EVT. Os seus exemplos de património artístico não mais se limitaram à análise tradicional Portuguesa de monumentos antigos, pinturas de Belas Artes e festas de índole religiosa. Em vez disso, ensinaram o conceito de transmissão e transformação cultural e valores de cidadania e promoveram o estudo de diversidade cultural como uma via para um maior entendimento do conceito de património. Trataram dos problemas que diariamente nos afectam, como seja a pobreza, a opressão, os direitos humanos. Era esperado que os estudantes se colocassem na posição do 'outro' e se envolvessem num diálogo crítico, através de um exame dos valores fundamentais.

\section{Análise de Exemplos do Curso de Mestrado em Educação Artística}

Foram diversas as investigações feitas no âmbito do Curso de Mestrado em Art, Craft and Design Education, primeiro Mestrado em Portugal neste âmbito da Educação Artística, a decorrer na ESEVC desde 1997, após assinatura de protocolo de colaboração com a então Universidade de Surrey Roehampton, em Londres. O Carnaval do 'Pai Velho' na Comunidade do Lindoso: Etnografia Educativa, Análise das Pinturas do Tecto da Igreja de S. Miguel: Investigação-Acção numa Escola de 10 Ciclo no Noroeste Português, Introdução do Estudo das Arte de Culturas Não-Ocidentais na Disciplina de Educação Visual e Tecnológica, Introdução da Escultura Tradicional (o Caso YAKA) no Currículo de 
Educação Artística no Secundário em Angola: uma Experiência Curricular, Uma análise às Práticas e Organizações Sociais e Culturais da Comunidade da Ilha de Luanda e suas Implicações no Currículo de Arte do Ensino Primário Angolano, Investigação sobre Arte Religiosa: A Festa das Cruzes, de Rui Oliveira Santos, Investigação sobre Artesanato: Bordado Regional de Viana do Castelo, de Ana Cristina Lima, Formação Vocacional de Técnicos para Apoiar a Criação Artística: Um Estudo de Caso na Comunidade Portuguesa de Vila Nova de Cerveira, de Margarida Leão, Investigação sobre Artesanato: Rendas de Bilros de Vila do Conde, de João Macedo e Valores Estéticas na Vida do Quotidiano: Investigação na Região Rural de Carrazeda de Ansiães são alguns dos muitos estudos que aqui se realizaram nas diversas edições de Mestrado que decorreram entre 1997 e 2006. Apenas se resumirão aqui quatro:

\section{Análise das Pinturas do Tecto da Igreja de S. Miguel: Investigação-Acção numa}

Escola de $1^{\circ}$ Ciclo no Noroeste Português foi realizada por uma professora Generalista do $1^{0}$ Ciclo, Maria Rosário Ferreira, em 2001. Trata-se de uma investigaçãoacção durante a qual Rosário tentou investigar a possibilidade de usar uma estratégia de ensino que incentivasse crianças a responder e a falar sobre obras de arte, baseada em modelos de autores Britânicos e Americanos, tais como Taylor (1986) e Feldman (1985) e pudesse ser aplicada com sucesso no contexto Português, mais precisamente numa escola rural, de $1^{\circ}$ ciclo (escola primária), no Noroeste Português. O problema específico desta investigação era a constatação da ausência de exploração do domínio curricular relacionado com o conhecimento e compreensão da arte na educação artística, ao nível do $1^{\circ}$ ciclo, em Portugal. As crianças não eram capazes de fazer julgamentos informados sobre as obras de arte e não aprendiam a valorizar e a respeitar o seu próprio património cultural e o dos outros povos e culturas, embora isso fosse uma das grandes finalidades do currículo nacional Português. A investigação-acção foi a posição teórica e metodológica assumida por Ferreira para pôr em prática uma experiência curricular. Os dados foram recolhidos através de uma câmara de vídeo, de folhas de perguntaresposta, por uma observadora independente e pelas reflexões registadas sistematicamente num diário da investigadora. Os dados dos intervenientes garantiram a fiabilidade dos resultados. Para esta investigação-acção, escolheram-se as pinturas barrocas do tecto da Igreja de S. Miguel, para serem analisadas pelas crianças, por serem uma parte importante do património cultural local. Foram feitas referências aos domínios do ensino/aprendizagem artística, segundo Allison (1982). A investigadora pesquisou alguns autores Ingleses e Americanos que escreveram sobre estratégias críticas para crianças responderem e falarem sobre trabalhos de arte e utilizou os modelos de Taylor (1986) e de Feldman (1982) na igreja de S. Miguel. A investigaçãoacção foi considerada um método de investigação muito útil, que beneficiou 
consideravelmente o trabalho da investigadora, ao permitir-lhe um olhar muito crítico sobre a sua própria prática. Os modelos de crítica de arte testados foram considerados adequados ao contexto Português de escolas de $1^{\circ}$ ciclo e contribuíram para desenvolver nos estudantes alguma consciência sobre o seu património cultural. Outra conclusão a que se chegou nesta investigação foi que é evidente a ausência de investigação em educação artística em Portugal, com professores generalistas que leccionam Expressão Plástica no $1^{\circ}$ ciclo de Ensino Básico e que esses professores necessitam de programas de formação contínua para reflectirem sobre estratégias que possam facilitar-lhes o desenvolvimento do conhecimento e compreensão do seu património artístico.

\section{Uma Análise Às Práticas e Organizações Sociais e Culturais da Comunidade da Ilha de Luanda e suas Implicações no Currículo de Arte do Ensino Primário} Angolano foi realizada, em 2003, por Jorge Gumbe, Artista Plástico e Professor de Arte no Instituto Nacional de Formação Artística e Cultural do Ministério da Cultura Angolano. A finalidade desta investigação incidiu concretamente na pesquisa e documentação referente ao Kákulu, o ritual da "Kyàndá (divindade da água)", ligado à cultura tradicional angolana, com fortes raízes na comunidade da Ilha de Luanda, na perspectiva de valorização das tradições culturais e da sua utilização pelos professores primários na disciplina de Educação Manual e Plástica, no âmbito da recente reforma do currículo nacional de arte nesse país. Tal utilização constituirá, segundo este investigador Angolano, uma via de conhecimento, promoção e compreensão do património cultural de Angola, por parte dos alunos. Gumbe (2005) fez uma análise de literatura internacional desenvolvida por educadores de arte Ocidentais e Africanos tais como McFee \& Degge (1977), Stuhr, Petrovich-Mwaniki \& Wasson (1992), Chalmers (1996), Mason (1995), Boughton (1999), Somjee (1999) e Moura (2000) e alega que todos defendem que os conceitos antropológicos ajudam a identificar e a descrever a arte de diversas culturas, sendo para tal necessário o seguinte:

desenvolver estudos etnográficos que liguem arte e cultura no sentido de promover a compreensão entre os povos; atribuir importância ao uso dos materiais locais para a produção de obras; conceitos antropológicos antes de os aplicarem nas suas salas de aula. (alterei só a formatação).

Após a revisão da literatura, foi usado o método etnográfico para recolha, descrição, análise e interpretação do Kákulu, o ritual da "Kyàndá (divindade da água)" na comunidade da Ilha de Luanda. As questões da investigação foram as seguintes: 
(i) Qual é a origem desta tradição cultural e como apareceu em Angola, nomeadamente na comunidade da Ilha de Luanda?

(ii) Como é que a comunidade local interpreta, actualmente, esta tradição cultural?

(iii) Que influências esta tradição cultural terá sofrido, após a independência política de Angola, na forma como as populações locais a vêem?

(iv) Quais são as mensagens, símbolos, imagens, imaginários e os significados estéticos que esta cultura veicula?

(v) Como pode esta tradição ser explorada cultural e artisticamente e incluída no currículo nacional de arte do ensino primário? (alterei a formatação)

O ritual foi documentado através das técnicas de recolha de dados tais como: a observação participante, o diário, a fotografia e entrevistas semi-abertas com membros da comunidade. Para validar os dados da investigação, foi usada a triangulação. Foram recolhidas e documentadas imagens visuais do Kakulu e analisadas e interpretadas no contexto cultural para o seu uso como recursos no ensino e na formação de professores primários, na disciplina de Educação Manual e Plástica. Estas imagens foram consideradas como um meio de expressão cultural e como formas de arte usadas em diferentes contextos e com diferentes funções. Os temas foram definidos tendo em conta as questões da investigação, para comparar e relacionar as mensagens, símbolos, imagens, ideias e significados estéticos do ritual, com o objectivo de o documentar. 0 estudo do contexto cultural do ritual e das suas imagens visuais demonstrou ser um recurso adequado para motivar os alunos para a aprendizagem na educação artística. 


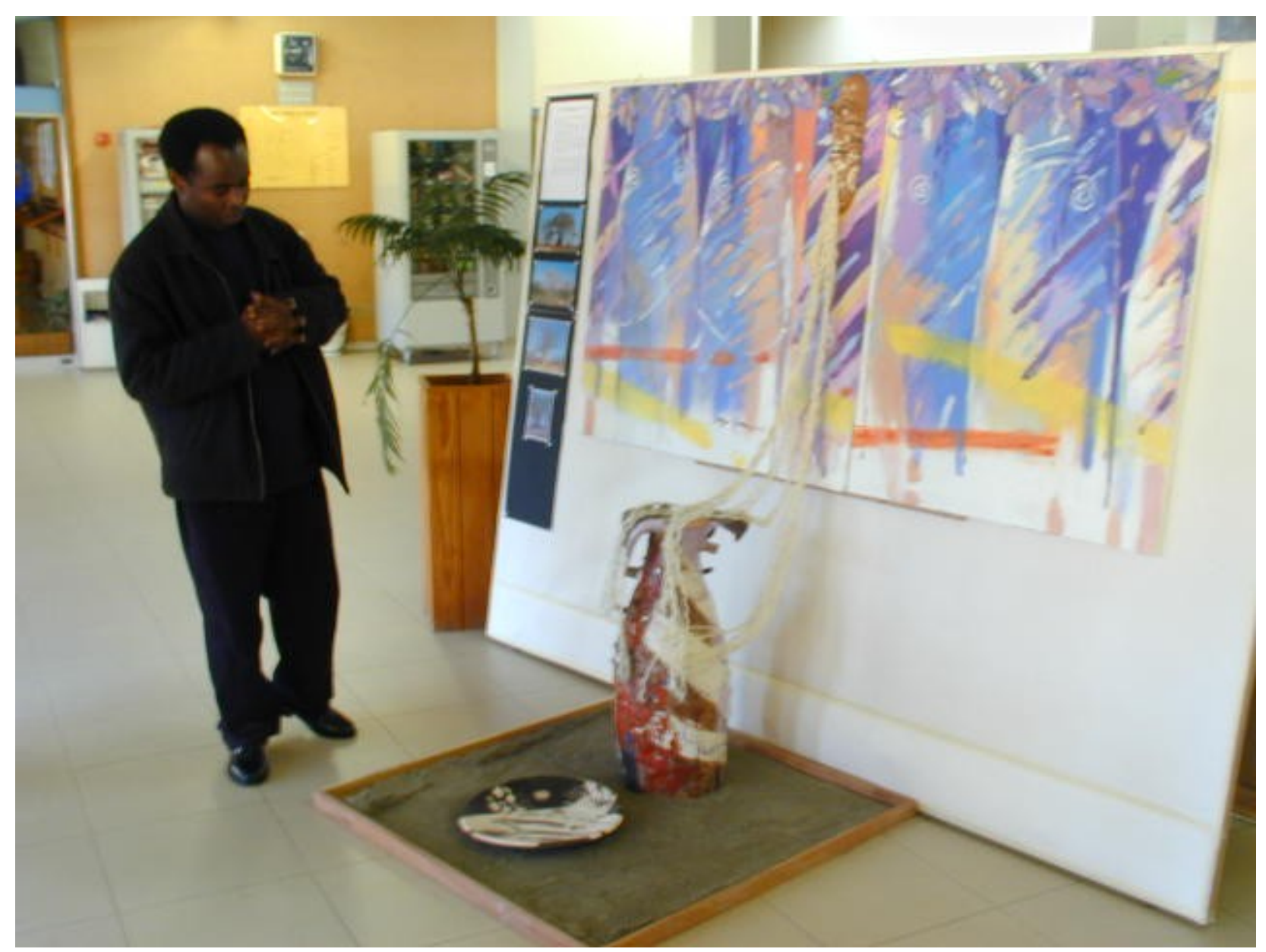

Fig.4: "Kyàndá" (divindade da água) -de Jorge Gumbe

\section{Formação Vocacional de Técnicos para Apoiar a Criação Artística: Um Estudo de Caso na Comunidade Portuguesa de Vila Nova de Cerveira foi a investigação} realizada por Margarida Leão, Artista Plástica e Professora de Arte do 30 Ciclo do Ensino Básico, em 2004. O objectivo desta pesquisa foi o de investigar o treino vocacional de técnicos para apoio à criação artística, tendo como finalidade principal analisar as potencialidades de desenvolvimento de cursos nas áreas da criação artística, com particular referência à comunidade artística radicada em Vila Nova de Cerveira, no Norte de Portugal e fazendo fronteira com Espanha. A pesquisa envolveu 117 alunos e 37 encarregados de educação da Escola EB 2/3 de Valença e, na Associação Projecto-Núcleo de Desenvolvimento Cultural, dois artistas, seleccionados intencionalmente. Foi realizada uma revisão de literatura que incidiu sobre o desenvolvimento local, abandono escolar e treino vocacional, com particular referência ao contexto Português. A abordagem metodológica foi a pesquisa qualitativa, de natureza interpretativa: estudo de Caso, na perspectiva de uso multi-métodos, nomeadamente entrevista semi-estruturada, inquéritos, observação e análise de legislação vigente em Portugal, sobre os temas abordados. Os dados recolhidos foram analisados e avaliados de modo a estabelecer as necessidades dos artistas e estudantes que abandonam a escola e como a Associação 
Projecto-Núcleo de Desenvolvimento Cultural, através das suas infra-estruturas, poderia responder a essas necessidades. Os resultados da análise mostraram que os estudantes, ao findarem a escolaridade obrigatória, reconhecem a sua falta de pré-requisitos para frequentar a Universidade e a falta de empregos e muitos desejam um curso intermédio que Ihes dê independência financeira e realização pessoal. Por sua vez, ficou também demonstrado que os dois entrevistados são unânimes na necessidade da criação de uma escola-oficina que dê treino a técnicos de oficinas artísticas, dando a oportunidade aos jovens de se valorizarem profissional e pessoalmente e contribuírem para o desenvolvimento da região. As conclusões deste estudo foram de que existem recursos disponíveis na região de Cerveira (Associação Projecto-Núcleo de Desenvolvimento Cultural, a Casa do Artista, a Galeria e a Bienal de Cerveira) que podem contribuir, através da sua actividade cultural e artística para o programa de treino artístico de técnicos. O estudo recomenda a continuação de outras pesquisas sobre o papel dos professores de arte e como estes poderão utilizar os recursos tecnológicos do projecto da Bienal, num programa artístico, para o treino de técnicos de apoio à criação artística. Ao findar esta pesquisa, percebe-se a necessidade do estabelecimento de treino vocacional para responder às necessidades de artistas e de jovens e que esta pesquisa foi apenas o início de um longo caminho a percorrer em áreas semelhantes.

\section{Valores Estéticos na Vida do Quotidiano: Investigação na Região Rural de}

Carrazeda de Ansiães foi realizada por Hélder de Carvalho, Artista Plástico e Professor do Ensino Superior Politécnico, Escola Superior de Educação de Bragança, em 2005. A finalidade deste estudo foi de investigar como o ensino da cultura, da estética e da educação artística podem contribuir para a consciencialização de valores culturais e tradições de um povo. A investigação começou pela revisão da literatura sobre as relações entre a cultura e a estética do quotidiano. Esta pesquisa, qualitativa e descritiva, usou um método de investigação etnográfico e os dados foram recolhidos através da realização de cinco entrevistas, conduzidas na comunidade rural de Carrazeda de Ansiães, localizada em Trás-os-montes. Os dados recolhidos durante o trabalho de campo foram analisados individualmente e comparativamente de forma a identificar as preocupações e preferências estéticas das pessoas e a forma como elas valorizam a preservação do seu património. Os resultados das entrevistas a estas cinco pessoas confirmaram que as suas preferências estéticas eram bastante semelhantes e constatouse que havia uma grande lacuna ao nível de documentos escritos sobre as preferências estéticas de hábitos e costumes do quotidiano, em contextos rurais como este. Concluiuse que as tradições locais e o contexto cultural influenciam enormemente os hábitos, crenças e valores estéticos desta comunidade e que a escola, infelizmente, não promove estudos regionais culturais, chegando mesmo a ignorar as suas próprias tradições. Para 
compreender a natureza cultural da arte, Carvalho afirma que a educação artística necessita de explorar as suas relações com a antropologia, enfatizando a aprendizagem de outros métodos e técnicas de trabalho, no uso prático de outros materiais. Esta pesquisa recomenda mais investigação sobre o papel da educação artística de forma a promover um melhor conhecimento de contextos rurais, pois isso pode contribuir para reforçar a necessidade de preservação e promoção da identidade patrimonial Portuguesa.

\section{Projectos Internacionais}

\section{Inglaterra}

Com Inglaterra, em 1994, coordenei um Projecto juntamente com Steve Bruntlett, professor do Curso de Mestrado em Educação Artística na Universidade de Montfort, Leicester (DMU), Inglaterra. Tratava-se de um Projecto que pretendia examinar o papel educativo do multimédia interactivo no ensino do Património, nas aulas de arte. 0 Projecto foi financiado pela Junta Nacional de Investigação Científica e Tecnológica (JNICT) e teve o apoio dos professores e alunos do Departamento de Comunicação e Expressões Artísticas, área de EVT, professores de arte do Concelho de Viana do Castelo, artesãos, Presidente da Região do Alto Minho, Francisco Sampaio e o Director do Museu Municipal de Viana do Castelo, António Matos Reis. O Projecto decorreu entre Julho de 1995 e Julho de 1996 e teve as seguintes finalidades:

- Identificar a forma como e os Multimédia Interactivos podem ser usados na melhoria do ensino e aprendizagem no $2^{\circ}$ e $3^{\circ}$ ciclos do Ensino Básico;

- Conhecer como é que os elementos dos Multimédia Interactivos - texto, imagens, animação e som - podem ser combinados e produzem uma nova estratégia pedagógica;

- Facilitar o uso do multimédia educativo interactivo nas escolas, através da realização de cursos de formação de professores;

- Adquirir conhecimento sobre a utilização dos objectos de arte e artesanato guardados em museus ou recolhidos na comunidade no desenvolvimento de aplicações de Multimédia Interactivos nas escolas;

- Conhecer novos processos de ensino - aprendizagem nas escolas, usando as capacidades e as possibilidades que a informática e os Multimédia Interactivos oferecem.

Este Projecto surgiu na sequência de cursos intensivos de férias relacionados com a utilização de tecnologia multimédia e programas de computador diversos, que decorreram na Escola Superior de Educação de Viana do Castelo (ESEVC) e tiveram os seguintes objectivos: 
- Preparar professores de EVT da região e estudantes do curso de EVT da ESEVC, para o uso dos multimédia e na produção de materiais educativos estimulantes e pedagogicamente motivadores, relacionados com património;

- Desenvolver competências tecnológicas e de investigação na equipa do Projecto que incluía dois professores que estavam a fazer o seu Curso de Mestrado na Universidade de Montfort, Leicester;

- Produzir exemplos multimédia, com base no estudo do Museu Municipal, ou nas actividades tradicionais relacionadas com o artesanato da região, de forma a serem usados em escolas de $1^{\circ}$ e $2^{\circ}$ ciclos de Ensino Básico como um recurso de ensino-aprendizagem para estudos críticos, antropológicos e de design, de forma a desenvolver nos estudantes a noção de preservação da sua herança cultural rural.

$\mathrm{Na}$ primeira fase deste projecto, foram documentados uma série de artefactos e processos artesanais, usando a fotografia e o vídeo. Estes recursos e a informação contextual formaram a base dos recursos de ensino-aprendizagem que se construíram. 0 Projecto pretendia documentar exemplos do património artístico do Alto Minho, de forma a permitir que os alunos e professores de escolas Inglesas pudessem compreender algo sobre os artefactos da cultura minhota, muitas vezes visitada apenas em tempo de férias e compararem-nos com os seus artefactos através de tecnologia multimédia e também da Internet.

Em Dezembro de 1995, realizou-se no Museu de Viana do Castelo uma Conferência, apoiada pelo Director do Museu e à qual assistiram mais de 100 participantes para além dos alunos e professores de Arte da ESEVC. Foram feitas apresentações pelos formandos da equipa do Projecto e pela directora da Cooperativa de Artesanato de Vila Verde. Posteriormente, realizou-se, no mesmo local, outra sessão, destinada a professores do ensino secundário, com o objectivo de lhes dar a conhecer os resultados das investigações em curso e de os sensibilizar, também, para o interesse dos multimédia na educação, especialmente se utilizarem programas estudados especificamente para o ensino. Especialistas do Museu de Etnologia, em Lisboa, tais como Benjamim Enes Pereira, foram consultados. Os CDs Produzidos envolveram as seguintes recolhas:

- Bordados (artefactos) - Viana do Castelo - Armanda Pereira Vaz Esperança (artesã);

- Artesanato - Cestas (artefactos e processos artesanais) - Lisboa, Aveiro - Freixo Artesãos anónimos; 
- Lenços do Namorados (artefactos) - Vila Verde - Da Maria Conceição (Directora da Cooperativa);

- Lenços do Namorados (artefactos) - Professor Frade (professor) - Esc. De $2^{\circ}$ Ciclo de Ermesinde;

- Cestas Floridos (processo artesanal) - Perre - Hipólito Duarte Pereira (professor);

- Cestas (artefactos e processo artesanal) - Forjães - José Manuel Branco (professor);

- Candeeiro de Tecto (processo artesanal) - Ponte de Lima - José Manuel Pinto Armada (artesão);

- Ramos de Andor (processo artesanal) - Viana do Castelo - Juberta Lajoso Silva (professora e artesã);

- Tecedeira: Saia e Avental - (artefactos e processo artesanal) - Perre - Luisa Alves Jácome (artesã);

- Funilaria (artefactos e processo artesanal) - Carapeços - Luis Oliveira de Faria(artesão).

Uma das mais importantes conclusões a que se chegou foi que a maioria dos CD-Rom, ditos interactivos, que se encontram no mercado deixam pouco espaço à actividade e à criatividade dos seus utilizadores, pois baseiam-se em esquemas rígidos, em que apenas se deixa ao utilizador a escolha da cronometria da leitura de cada uma das suas componentes e a possibilidade de seleccionar uma ou outra ou de regressar a um dos subtemas, quando se pretendesse, seleccionando a correspondente opção no menu. Os professores de EVT que participaram neste Projecto introduziram componentes que funcionaram de estímulo para os utilizadores ou proporcionaram-lhes a hipótese de adicionar ao programa os seus contributos pessoais, quer sob a forma de comentários escritos, quer sob a forma de desenho. Assim se produziram recursos primários muito bem documentados e muito relevantes para o ensino - aprendizagem de educação patrimonial, nas suas salas de aula de arte.

Apesar do financiamento ter terminado, esta equipa de professores nunca mais parou de investigar esta área, podendo dar continuidade, de forma autónoma, pondo em prática as competências, técnicas e estratégias de ensino-aprendizagem explorados neste Projecto. Será importante mencionar igualmente que esta foi a primeira oportunidade que os alunos de arte tiveram, na ESEVC, de exploração da tecnologia multimédia. Evidenciaram grande empenho e motivação para utilizarem estes media como uma forma eficaz e cativante de divulgarem as suas ideias sobre património. 
Outra conclusão para futuros projectos é que trabalhar com estudantes e professores motivados, com experiência na produção de arte e design através do computador, é uma forma muito eficaz de desenvolver recursos educativos multimédia para o ensino do património em aulas de Educação Artística. Segundo Matos Reis (2000), Director do Museu na época, ficou também patente o modo como, na sequência da visita ao Museu, as imagens disponibilizadas em formato digital podem ser usadas para explorar os valores culturais e artísticos das peças expostas (p.15).

\section{Espanha}

Encontros Pedagógicos entre Norte de Portugal/Galiza tiveram o objectivo primordial de divulgar tradições patrimoniais junto dos alunos, contribuindo para a sua valorização e enriquecimento cultural. Entre 1999 e 2002, realizaram-se em Viana do Castelo, no Pavilhão de Exposições da Associação Industrial do Minho, a $1^{a}$ e a $2^{a}$ Feira da Educação/Expo Festa da Educação. Os eventos resultaram da congregação de esforços de um conjunto de projectos desenvolvidos ou apoiados pelo ICE (Instituto das Comunidades Educativas), da Escola EB 2,3 de Frei Bartolomeu dos Mártires, da Escola Superior de Educação de Viana do Castelo e da Câmara Municipal de Viana do Castelo, entre outras instituições que, no decurso da sua organização, se solidarizaram com a iniciativa. Foram participantes:

- 14 Jardins-de-infância e um Projecto de Educação de Infância Itinerante (Pré-escolar na Casa, de Lugo, Espanha);

- 15 Escolas do 10 CEB;

- 4 Escolas dos $2^{\circ}$ e $3^{\circ}$ CEB, que implicaram cerca de 3000 crianças;

- 3 Instituições do Ensino Superior;

- 3 Escolas Profissionais, que implicaram cerca de 250 estudantes da formação inicial;

- Cerca de 120 professores e educadores (portugueses e espanhóis);

- Aproximadamente, 30 auxiliares de acção educativa;

- Cerca de 60 actores das comunidades locais (pais, artesãos, "amigos" dos projectos, elementos de associações locais);

- 4 técnicos autárquicos.

Estas actividades tiveram como finalidades:

- Promover a confluência Educação/Cultura; 
- Promover a visibilidade dos processos sociais locais, ao nível do desenvolvimento do processo educativo, nas suas dimensões formais, não formais e informais;

- Induzir a construção de Projectos Educativos a partir de uma racionalidade que valoriza/rentabiliza os saberes e patrimónios locais.

Do conjunto das finalidades anteriormente formuladas decorreram os seguintes objectivos:

- Criar um momento forte de mostra alargada de produtos, de intercâmbio e de reflexão entre crianças, educadores, professores, associações locais, autarquias e outras instituições dos meios rurais e urbanos;

- Promover a valorização das culturas locais;

- Criar condições para a construção de novas parcerias que viabilizem o desenvolvimento de Projectos Educativos efectivamente assentes nas necessidades e nos interesses locais;

- Ensaiar novas formas de exercício da cidadania a nível local.

Pretendendo-se que a Expo Festa da Educação fosse uma iniciativa/mostra alargada da diversidade da acção educativa e de valorização de todos quantos nelas participariam, a construção desta induziu a participação do maior número possível de actores locais, transformando-a num tempo e num espaço de formação e desenvolvimento colectivos em que cada interveniente fosse, simultaneamente, produtor de conhecimento, de soluções para os problemas e de si mesmo (SIMÕES, PALMA e MARQUES, 2001).

Entender a Educação como acto de Cultura significou valorizar/rentabilizar as culturas locais e pôr em equidade os níveis formais, não formais e informais que o processo educativo encerra (SIMÕES, PALMA e MARQUES, 2001). Significou, também, trabalhar na construção de parcerias alargadas que, por sua vez, ao desenvolverem novas relações inter-institucionais, induziram o aparecimento de novos olhares sobre a sociedade e a emergência de novas práticas sociais. Neste sentido, a realização destes eventos, enquanto indutora de movimentos sociais diversos no processo da sua organização e de prazer colectivo no momento em que aconteceu, foi um contributo pertinente para o Desenvolvimento no concelho de Viana do Castelo.

A Escola EB 1,2,3 de Frei Bartolomeu dos Mártires, apoiada cientificamente ao nível das áreas de EVT e Educação Musical (EM) da ESEVC, desenvolveu este Projecto através de trabalhos de pesquisa, exposições, participação em actividades dinamizadas pela autarquia local, visitas de estudo, workshops e a criação de material de apoio, tal como 
publicações, vídeos e postais. Nas semanas em que decorreram os eventos, deu-se a conhecer o logótipo criado por um grupo de alunos nas aulas de um estagiário de EVT, destinado a identificar o projecto de parceria Norte de Portugal/Galiza. Tiveram lugar conferências subordinadas ao tema Descoberta do Património, mostras de ensino através de apresentações de quiosques multimédia, livros e feiras de artesanato.

\section{Implicações Educativas}

Para que professores generalistas e especialistas estejam aptos a desempenhar com confiança o papel de mediadores entre o universo cultural das suas crianças e o universo dos saberes históricos e culturais sistematizados, necessitam de desenvolver o gosto pela investigação e pela busca de informações e conceitos, muitas vezes escassos, sobre os tópicos em estudo. A reflexão pessoal sobre esta temática, nos últimos anos, no Departamento de Expressões Artísticas da Escola Superior de Educação de Viana do Castelo, conduziu à formulação das seguintes questões:

- É possível melhorar o ensino das artes, em Portugal, sem uma cultura de investigação?

- Como criar uma prática sistemática de investigação nestas áreas?

Como resposta a estas questões, desenvolveu-se um quadro conceptual que permite preparar e incentivar os docentes para a investigação. Introduziram-se novas disciplinas tais como Métodos de Pesquisa (no Curso de EVT e no actual Curso de Gestão Artística e Cultural-GAC), Antropologia Estética e Visual, Escola e Património, Web Design e Multimédia, Ateliê de Construção de Materiais Pedagógicos, no plano de estudos da formação inicial dos professores de EVT da ESEVC, bem como a obrigatoriedade de desenvolvimento de um projecto individual de investigação (Seminário de Investigação no curso de GAC).

Desenvolveram-se, paralelamente, contactos com Instituições estrangeiras de formação de professores e de Gestores no sector da Gestão Artística e Cultural, tais como a Montfort University e Surrey Roehampton University, com sólidas tradições de investigação nas áreas do ensino artístico, para a implementação, em Portugal, de cursos de férias intensivos, dos primeiros Cursos de Mestrado nos domínios das Artes Visuais e da Educação Musical e, actualmente, o Projecto Images and Identity- Improving Citizenship Education through Digital Art, financiado pelo Programa Comenius (2008/2010) e Treaty of Windsor (2009/2010), que envolveu seis parceiros Europeus. 
Em Novembro será apresentado o resultado da investigação realizada na ESEVC, no âmbito deste Projecto, na República Checa, no Congresso Internacional da InSEA 2010, sobre Visual Literacy (ver website http://www.roehampton.ac.uk/images-andidentity/index.html

Estas iniciativas têm tido como principais objectivos a criação de um grupo de professores de Artes aptos a desenvolver projectos de investigação nas suas Instituições; a melhoria do nível de ensino na área científica das Artes e Humanidades e a formação contínua de um corpo docente na ESEVC capaz de assumir responsabilidades crescentes no desenvolvimento de projectos de investigação.

Estreitaram-se os laços de cooperação entre o Departamento de Artes da ESEVC e o Centro de Estudos da Criança da Universidade do Minho, Centro de Pós Graduação da Universidade Federal de Belo Horizonte, Brasil e Centro de Pós Graduação da Universidade de Roehampton, Londres sendo a organização das Conferências Internacionais, anualmente e a partir de 2005, uma das consequências dessas acções. Procura-se, finalmente, desenvolver uma estrutura de apoio aos antigos alunos da ESEVC e aos professores cooperantes, através de cursos de Formação Contínua que Ihes permitam continuar a formação ao longo da sua vida profissional, motivando-os, actualizando-os científica e pedagogicamente e colaborando nos seus projectos individuais ou de escola

\section{Conclusão}

A preocupação prioritária no acompanhamento da evolução destas investigações tem sido consciencializar os nossos estudantes para um maior conhecimento e compreensão das artes numa perspectiva multicultural, sem hierarquias, convidando-os a reflectirem sobre as relações entre a 'alta' e a 'baixa' culturas e ajudá-los a reconhecer que a produção e a recepção da cultura são produtos de uma mentalidade colectiva e a aceitar que os artistas são afectados pelo seu contexto histórico - cultural. A busca da integração da produção artística não deve perder de vista a pluralidade das concepções e a polifonia das culturas que modelam a nossa identidade. Assim, a educação deve criar mecanismos que dêem, a todos, iguais condições para uma actuação social mais crítica e responsável. O ênfase multicultural contrapõe-se à tendência de abordagens que privilegiam apenas a herança cultural europeia, ao ensino de arte ocidental que ignora as vastas possibilidades das tradições artísticas africanas, asiáticas e outras. Nesta perspectiva, não rompemos com o passado da história da arte, com as tradições artísticas anteriores, eruditas e populares, mas promovemos o diálogo entre linguagens, abarcando outros domínios do conhecimento, lugares geográficos e sociais, culturais, 
arquitectónicos, políticos, económicos e outros, dando assim resposta ao multiculturalismo e interdisciplinaridade.

Tal como estas investigações têm revelado, os estereótipos estão largamente disseminados na escolaridade Portuguesa. O currículo de EVT reflecte e produz visões estereotipadas de pessoas e das artes dos países em desenvolvimento apelidando-as de 'exóticas' ou 'primitivas'; isso tem contribuído para perpetuar a ideia de que a arte popular é menos importante do que a arte erudita e que a melhor arte do mundo é a que é produzida pelos Europeus (CHALMERS, 1996). No chamado currículo oculto da escolaridade Portuguesa, muitos valores são transmitidos a nível consciente ou inconsciente e a formação de turmas homogéneas, com as tendências que isso promove na interacção entre os estudantes e estudantes e professores, tem contribuído para a formação de estereótipos e preconceitos.

Nestas investigações, foi o currículo de EVT que foi questionado, pela forma negativa como lida com as questões de estereótipo e de mudança cultural. O conceito de património e cultura foram desafiados, contrariando a tendência de os leccionarem como sendo algo monocultural, mais estático do que dinâmico. Ao longo destas investigações, todos os intervenientes concluíram que o conhecimento do passado era crucial para a compreensão das injustiças presentes. Foi igualmente crucial trabalhar em interdisciplinaridade com professores de história, sociologia, antropologia e português, no desenho de novos caminhos de ensino aprendizagem sobre a Expansão Portuguesa, o colonialismo, as rotas da escravatura, as relações de poder nas sociedades, os conceitos de 'opressor' e de 'oprimido', de discriminação e de desigualdade social. Foi essencialmente esta estratégia que facilitou a aprendizagem de questões relacionadas com direitos humanos, cidadania e igualdade de oportunidades. Utilizaram-se estratégias de crítica de arte, através de um método antropológico, que requeria dos participantes uma descrição e análise de imagens e artefactos de diversas culturas europeias e não europeias. Ao fazê-lo, iam analisando exemplos de arte de outros continentes e levantando questões acerca deles.

Concluiu-se que as leis gerais da educação são apropriadas para a educação Multicultural, pois envolvem o conceito de Direitos Humanos. O principal problema é que elas não são transferidas para a prática. As mudanças curriculares introduziram modificações a esta legislação, a nível local, de forma a garantir que as escolas se adaptem às necessidades emergentes e contemplem os princípios legislativos que já existiam. Algumas destas investigações concluíram, também, que os regulamentos internos das escolas necessitam de ser revistos, de forma a garantirem igualdade de 
oportunidades, justiça e liberdade de expressão para todos os estudantes, de acordo com os princípios legislativos nacionais e que os procedimentos estruturais devem ser respeitados nas escolas portuguesas assegurando que se lide apropriadamente com incidentes de discriminação baseados em questões de género, religião, etnia, ou classe social.

É necessária informação, por parte dos órgãos de direç̧ão da educação artística, para uma orientação curricular multicultural ao nível escolar e devem ser estabelecidos mecanismos de controlo que assegurem que os direitos de todos os estudantes sejam respeitados na prática. Outra conclusão, com implicações para a política educativa, é que os valores chave de uma democracia podem ser desenvolvidos através de actividades colaborativas com a comunidade existente e organizações activistas e com o desenvolvimento de mais investigação ao nível das instituições de ensino superior; e que este tipo de colaboração pode apoiar-se numa análise crítica relativa à actual política legislativa. As equipas das investigações concordaram que existe uma necessidade de uma maior reflexão e debate sobre o significado de valores e padrões tradicionais na educação portuguesa, particularmente no que respeita à aplicação inconsciente de dicotomias sociais tais como 'rico e pobre', 'rural e urbano', 'maioria e minoria', 'estudantes brancos e sem serem brancos' e 'rapazes e raparigas'.

A finalizar gostaria de referir, para além dos aspectos citados e óbvios, mais um ponto positivo destas parcerias e, para mim, particularmente sensível: o alargamento de relações humanas e o estreitamento das mesmas. O nosso quotidiano é, frequentemente, frenético e com cada vez menos tempo disponível para os contactos humanos. Numa época em que a incerteza se apoderou da educação, torna-se urgente o entrelaçar da responsabilidade com os projectos a construir, permitindo que abram algumas pistas para a construção de um mundo melhor, onde a difusão do saber se faça através de uma sistemática reflexão em torno das condições da aprendizagem, bem como da formação daqueles que estão envolvidos na complexidade das práticas pedagógicas e da formação permanente, explorando o conceito de rede de formação de pessoal, como um instrumento estratégico de mudança.

*Etnocentrismo refere-se à tendência negativa em todos os seres humanos para avaliar valores, comportamentos e características de outros grupos étnicos a partir da sua própria perspectiva (CHALMERS, 1996). 


\section{Referências}

ALLISON, B. (1972). Art Education and Teaching About the Art of Asia and Latin America. London: VCOAD Education Unit.

ALLISON, B. (1992). A Global Perspective to Curriculum Development in Art Education, comunicação integrada na $1^{a}$ Conferência Internacional sobre Educação Artística International perspectives in art education, Viana do Castelo: Escola Superior de Educação, Instituto Politécnico de Viana do Castelo.

ASSEMBLEIA DA REPÚBLICA (1986). Lei 46/86 de 14 de Outubro (Lei de Bases do Sistema Educativo). Lisboa: DR.

BANKS, J. (1994). Multiethnic Education, Theory and Practice. United States: Allyn and Bacon.

BARBOSA, P.G. (1982). 'Património Cultural', In Cadernos FAOJ, Series A, (20), Lisboa: Edições FAOJ.

BARRETO, J. (2002) Provérbios Populares, Portugal, Unidade Didáctica, documento policopiado. Viana do Castelo: ESEVC.

BERNARDO, F. (2002) Graffitis na Cidade de Viana do Castelo, Portugal, Unidade Didáctica, documento policopiado. Viana do Castelo: ESEVC.

BLANCO, A.G. (1988). Didáctica del Museu: el Descubrimiento de los Objectos. Madrid: Ediciones de la Torre.

BOUGHTON, D. (1999) Framing Art Curriculum and Assessment Policies in Diverse Cultural Settings, In BOUGHTON, D. \& MASON, R. (eds). Beyond Multicultural Art Education: International Perspectives. Germany: Waxmann Verlag GmbH, pp.331-348.

BOXER, C.R. (1988). Relações Raciais no Império Colonial Português, 1415-1825. Porto: Afrontamento.

BRAGA, R. (2003) Máscaras dos Índios de Jurupixuna, Brasil, Unidade Didáctica, documento policopiado. Viana do Castelo: ESEVC.

CARVALHO, H. (2005).Valores Estéticos na Vida do Quotidiano: Investigação na Região Rural de Carrazeda de Ansiães, tese de Mestrado policopiada, Viana do Castelo/Londres: Escola Superior de Educação/Roehampton University.

CHALMERS, G. (1996). Celebrating Pluralism: Art, Education and Cultural Diversity. Los Angeles: Getty Institute for Education in the Arts.

COWLISHAW, T. (1988). 'Multicultural Curriculum: a Personal Approach', In MASON, R. (ed.). Readings in art and design curriculum. Leicester: de Montfort University.

CURRÍCULO NACIONAL DE E.V.T. (1991). Programa do $2^{\circ}$ Ciclo do Ensino Básico. Lisboa: Ministério da Educação.

DASH, P. (1996). 'Addressing Stereotyping and Prejudice in Visual Images', In Reading visual texts: New Directions in Art Education: Conference Proceedings. London: Centre for Art Education and International Research, London: Roehampton University. 
DIAS, J. (1992). África. Lisboa: Comissão Nacional para as Comemorações dos Descobrimentos Portugueses.

EISNER, E. (1985). The Educational Imagination. New York: Macmillan.

FAUSTINO, P.S. (2001). Introdução do Estudo das Arte de Culturas Não-Ocidentais na Disciplina de Educação Visual e Tecnológica, tese de Mestrado policopiada, Viana do Castelo/Londres: Escola Superior de Educação/Roehampton University

FELDMAN, E.B. (1982). Varieties of Visual Experience (2nd edit.). New York: Harry, N. Abrams, Inc. Publishers.

FERREIRA, M.R. (2001). Análise das Pinturas do Tecto da Igreja de S. Miguel: Investigação-Acção numa Escola de 10 Ciclo no Nordeste Português, tese de Mestrado policopiada, Viana do Castelo/Londres: Escola Superior de Educação/Roehampton University.

GUMBE, J. (2005) Rituais como Conteúdo de Ensino Aprendizagem Através da Educação Artística em Escolas do 10 Ciclo Angolanas, In Actas da I Semana das Artes Perspectivas Internacionais na Educação Artística. Viana do Castelo: Departamento de Comunicações e Expressões Artísticas, 2 a 6 de Maio de 2005

(2003). Uma Análise às Praticas e Organizações Sociais e Culturais da Comunidade da Ilha de Luanda e suas Implicações no Currículo de Arte do Ensino Primário Angolano, tese de Mestrado policopiada, Viana do Castelo/Londres: Escola Superior de Educação/Roehampton University.

KENDALL, F.F. (1996). Diversity in the classroom: new approaches to the education of young children. New York: Teachers College Press.

LEÃo, M. (2004). Formação Vocacional de Técnicos para Apoiar a Criação Artística: Um Estudo de Caso na Comunidade Portuguesa de Vila Nova de Cerveira, tese de Mestrado policopiada, Viana do Castelo/Londres: Escola Superior de Educação/Roehampton University.

LEITE, C. (1997a). As palavras mais do que os actos? O multiculturalismo no sistema educativo Português, tese policopiada. Porto: Faculdade de Psicologia e de Ciências da Educação.

LEITE, C. (1997b). Multiculturalismo e educação escolar- cenários do passado e do presente, In Contributos da Investigação Científica para a Qualidade do Ensino. I Volume. Lisboa: Sociedade Portuguesa de Ciências da Educação.

LIMA, A. C. (2004). Investigação sobre Artesanato: Bordado Regional de Viana do Castelo, tese de Mestrado policopiada, Viana do Castelo/Londres: Escola Superior de Educação/ Roehampton University.

LOPES, S. (2003) Marionetes Japonesas do Teatro de Bunrako, Japão, Unidade Didáctica, documento policopiado. Viana do Castelo: ESEVC. 
KENDALL, F.F. (1996). Diversity in the Classroom: New Approaches to the Education of Young Children. New York: Teachers College Press.

MACEDO, J. (2005). Investigação sobre Artesanato: Rendas de Bilros de Vila do Conde, tese de Mestrado policopiada, Viana do Castelo/ Londres: Escola Superior de Educação/Roehampton University.

MACEDO, A. (2002). Mitos e Heróis, Guiné, Unidade Didáctica, documento policopiado. Viana do Castelo: ESEVC.

MACHADO, J.P. (1996). O grande livro dos provérbios. Lisboa: Editorial Notícias. MARCOUSÉ, R. (1974). Using Objects. New York: Van Nostrand and Reinhold.

MARTINS, P (2002).Artes e Religiões no Mundo, Unidade Didáctica, documento policopiado. Viana do Castelo: ESEVC.

MASON, R. (1990). 'Art and multicultural education: the new ethnicity in U.K.', in Journal of Art and Design Education, 9 (3), pp. 327-337.

MASON, R. (1991). 'Art teaching and research', in Journal of Art and Design Education, 10 (3), pp. 261-271.

(1992). 'Art education for cultural diversity, developments in the United Kingdom', paper presented at Issues III seminar DBAE and cultural diversity, Austin: Getty Center.

(1995). Art Education and Multiculturalism. Corsham: NSEAD.

(1996). 'International perspectives on multicultural art education', unpublished paper presented in the Conference at Institute of Art Education Tsukuba, University and Faculty of Education Utsunomiya University.

(1997a). 'Teacher based inquiry and art education', paper presented at the Educational research conference at Escola Superior de Educação, Viana do Castelo Polytechnic, Portugal.

(1997b). 'International perspectives on multicultural art education'. Acta Conference Hawthorne Institute, Melbourne.

(2001). Por uma Arte-Educação Multicultural. Campinas: Mercado das Letras.

MATOS REIS, A. (2000). Experiência de utilização dos multimédia no Museu Municipal de Viana do Castelo, In Museos y Museología en Portugal- una ruta ibérica para el futuro. Associación Española de Museólogos, pp. 13-1

MCFEE, J. \& DEGGE, R. (1977) Art, Culture \& Environment a Catalyst for Teaching. Wordsworth. Califórnia.

MINISTÉRIO DA EDUCAÇÃO (1993). Organização curricular dos programas, 20 Ciclo. Lisboa: DGEBS.

MIRANDA, M. (2002). Direitos da Criança, Unidade Didáctica, documento policopiado. Viana do Castelo: ESEVC.

MOURA, A. (2010) 'Percepção dos estudantes Portugueses sobre identidade nacional', In Revista Evidência; olhares e pesquisa em saberes educacionais, do Instituto Superior de 
Educação do UNIARAXÁ- Centro Universitário do Planalto de Araxá- número 6, pp.173 185, indexada na Edubase (Faculdade de Educação/Unicamp), ISSN 1808 -2327.

MOURA, A. (2009) Educação Cívica, Artes e Formação de Professores, In MOURA, A.; COQUET, E.(coords) Diálogos com a Arte. Braga, CESC - Minho University, pp. 127-146. ISBN 978-972-8952-14-3

MOURA, A. (2008). Art education as social intervention, In International Journal of Education through Art, Vol.4 (1), pp.29 - 43, Intellect Ltd. ISSN 1743 - 5234

MOURA, A. (1993). The effects of prior learning and a specialist art course on the acquisition of art vocabulary by Portuguese teacher training students. Tese de mestrado policopiada, Leicester: Universidade de Montfort.

(1999). 'Art Patrimony in Portuguese Middle Schools: Problems of Cultural Bias', In BOUGHTON, D. \& MASON, R. (eds). Beyond Multicultural Art Education: International Perspectives. Germany: Waxmann Verlag GmbH, 115-133.

(2000). Prejudice Reduction in Teaching and Learning Portuguese Cultural Patrimony. Tese de Doutoramento, Londres: Universidade de Surrey-Roehampton.

(2002). 'Uma Crítica Multicultural ao Ensino do Património Artístico nas Escolas do 20 Ciclo', In Revista Galega do Ensino, 34, 191-213.

NYARKOH, E.C. (1984) Ghana Cultural Renaissance. In Ort and Al Hurwitz. Africa.

OLIVEIRA SANTOS, R. (2003). Investigação sobre Arte Religiosa: A Festa das Cruzes, tese de Mestrado policopiada, Viana do Castelo/Londres: Escola Superior de Educação/ Roehampton University.

OliveIRA S. \& PEREIRA, R. (2005). O meu herói, Unidade Didáctica, documento policopiado. Viana do Castelo: ESEVC.

PACHECO, H. (1977). 'Um Povo, uma Cultura: Cultura Popular e Socialismo. Tentativa de uma Clarificação Necessária', In Revista o Professor, 3, 37-39.

(1984). 'Renovação Pedagógica', In Revista O Professor, 69, 27-54

(1985). Património Cultural Popular: Ambiente dos Homens. Porto: Areal Editores

(1993). 'Repensar a Ideia de Património', In Revista a Razão, 34, 55-57

(1995). 'A Etnografia Portuguesa é Preconceituosa', Revista Matosinhos,

$10,2-16$

PATRÍCIO, M.F. (1997). A escola cultural e os valores. Porto: Porto Editora.

PERAFITA, A. (1999). A Comunicação e a Literatura Popular. Lisboa: Plátano Eds Técnicas, Lda.

ROCHA-TRINDADE, M.B. (1993). Migrações e multiculturalismo, In Escola e sociedade multicultural. Lisboa: Ministério da Educação. Secretariado Coordenador dos Programas de Educação Multicultural.

SANTOS, M.A.M. (1999). Dicionário dos provérbios, adágios, ditados, máximas, aforismos e frases feitas. Porto: Porto Editora. 
SILVA, R. (2003) Máscaras Yaka, Unidade Didáctica, documento policopiado. Viana do Castelo: ESEVC.

SIMÕES, F.; PALMA, I.; MARQUES, J. (2002) Projecto Expo-Festa da Educação. Viana do Castelo:FBM/ CMVC/ICE

SOMJEE, S. (1999) Learning to be indigenous and being taught to be modern: The ethnography of lessons in art and material culture in Kenya. In Mason, R. \& Boughton, D. (Eds) Beyound Multicultural Art Education. International Perspectives. Munster. Waxmann,pp.199-211.

STUHR, P, PETROVICH-MWANIKI, L. AND WASSON, R. (1992). Curriculum Guidelines for the Multicultural Art Classroom, In Art Education, 45, pp. 16-24.

TAYLOR, R. (1986). Educating for art: critical response and development. London: Longman.

TEIXEIRA, V.L. (2000). O Carnaval do 'Pai Velho' na Comunidade do Lindoso: Etnografia Educativa, tese de Mestrado policopiada, Viana do Castelo/Londres: Escola Superior de Educação/ Roehampton University.

TELMO, I.C. (1986). O Património e a Escola, do Passado ao Futuro. Lisboa: Texto Editora

VAN-DÚNEM, F. (2003). Introdução da Escultura Tradicional (o Caso YAKA)no Currículo de Educação Artística no Secundário em Angola: uma Experiência Curricular, tese de Mestrado policopiada, Viana do Castelo/Londres: Escola Superior de Educação/ Roehampton University.

VIEIRA, F. (1993). Supervisão: uma Prática Reflexiva de Formação de Professores. Rio Tinto:Ed. ASA

WELCH, G. (1998). Research Methods and Issues in Music Education. Segunda Conferência Iberoamericana de Investigação Musical, Argentina: Buenos Aires.

WILLIAMS, R. (1983). Keywords: a vocabulary of culture and society. London: Fontana. 